\title{
MONITORAMENTO DE AVICULTURA A PARTIR DE TÉCNICAS DE VISÃO COMPUTACIONAL
}

\author{
Alyne Yumi Kodama Saltoratto ${ }^{1}$, Francisco Assis da Silva², Ana Claudia Ambiel Corral Camargo ${ }^{3}$, \\ Paulo Claudeir Gomes da Silva ${ }^{3}$, Lilian Francisco Arantes de Souza ${ }^{3}$. \\ ${ }^{1}$ Discente da Faculdade de Informática da UNOESTE. ${ }^{2}$ Docente da Faculdade de Informática da UNOESTE; ${ }^{3}$ Docente da \\ Faculdade de Ciências Agrárias da UNOESTE.
}

\section{RESUMO}

Para se ter uma criação de frangos com bons rendimentos, faz-se necessário um monitoramento constante por parte do produtor, onde as questões ligadas ao bem-estar animal devem ser vistos como um benefício econômico e não uma exigência. Com os grandes avanços da computação e com a atual capacidade de processamento de imagens, é possível baseando-se em frames de vídeos, extrair dados suficientes para propiciar um monitoramento da criação de aves (pintainhos). Para tanto, este trabalho apresenta uma ferramenta de monitoramento de avicultura a partir das imagens de frames de vídeos. Na metodologia proposta deste trabalho foram aplicadas técnicas para redução do brilho (intensidade) da imagem, assim como morfologia matemática e algoritmo de inundação como alguns dos procedimentos aplicados às imagens. Os dados de monitoramento das aves, gerados pelas análises das imagens, mostrou-se satisfatórios em determinar a frequência de permanência em certos locais das baias de criação.

Palavras-chave: análise de imagem; detecção de objetos; monitoramento de aves.

\section{MONITORING OF AVICULTURE FROM COMPUTER VISION TECHNIQUES}

\begin{abstract}
To get a poultry farming with good incomes, it is necessary to constant monitoring by the producer, where the issues related to animal welfare should be seen as an economic benefit and not a requirement. With the great advances in computing and with current capacity of image processing, it is possible based on frames from videos, to extract sufficient data to provide monitoring of chicken (chicks). Therefore, this work presents a tool for monitoring of aviculture from frame images from videos. In the proposed methodology of this research, techniques were applied to reduce the brightness (intensity) of the image as well as mathematical morphology and flooding algorithm as some of the procedures applied to images. Monitoring data of chicken, generated by analysis of the images, proved satisfactory in determining the frequency to stay in certain locations of the creation places.
\end{abstract}

Keywords: image analysis; object detection; monitoring of chicken. 


\section{INTRODUÇÃO}

Com a necessidade de atender um mercado mais exigente, com o decorrer dos anos a avicultura passou de indiferente a uma preocupação intensa pelo provimento de condições de ambiência adequadas na criação. Segundo Hyslop (apud NÄÄS et al., 2007, p. 326), pesquisas mostram a influência direta do ambiente inadequado de criação como um dos fatores que predispõem ao desenvolvimento adequado das aves.

Ambiência significa o espaço arquitetônico organizado e animado, e ao mesmo tempo psicológico, preparado para prover o melhor desempenho de quem o habita, ganhando assim, na última década, força pela necessidade de proporcionar melhoria às aves alojadas em baias de criação (PEREIRA, 2011). Segundo Gonyou (apud PEREIRA, 2011, p. 03), para se determinar o bem estar era utilizado somente a alimentação e a reprodução, mas estudiosos da Etologia ${ }^{1}$ sentiram a necessidade de estudar os estados emocionais, as liberdades de movimento e as experiências mentais.

Por meio do comportamento, é possível qualificar e identificar o bem-estar, sendo este realizado através de observações visuais, que consome muito tempo e a presença humana pode inibir 0 comportamento natural das aves, podendo

${ }^{1}$ Etologia: ciência que estuda o comportamento dos animais (SOUTO, 2005). assim gerar respostas não confiáveis (FALCO, 2010). Diante disso, recursos tecnológicos são essenciais para que as aves possam expressar seus comportamentos naturais, obtendo resultados mais produtivos $\mathrm{e}$ satisfatórios. A sequência de comportamentos ocorrido em um período de tempo constitui em uma importante fonte de informação, verificando os efeitos do ambiente sobre as aves. É de grande valia a possibilidade de uma técnica de aplicação adequada para monitorar o comportamento das aves no seu ambiente de criação, e com isso, ter a oportunidade de realizar uma análise com precisão a respeito do padrão de comportamento delas.

Segundo Nääs (2008), na avicultura o bem-estar dos animais é seu estado em relação às suas tentativas de se adaptar ao seu ambiente, envolvendo as questões físicas e mentais, sendo que a maioria das preocupações está centrada em como o animal se "sente" quando fica exposto ao confinamento ou manejo. Em geral, o bemestar das aves, segundo o autor, deve ser visto como um benefício econômico, de modo que, se não houver mudanças realizadas para uma melhor condição de bem-estar, pode-se resultar em uma produção de qualidade inferior, tendo um grande impacto em seu custo. Segundo Hellmeister Filho et al. (apud FALCO, 2010, 
p.13), em um sistema de criação, o bem-estar e a saúde animal devem ser considerados como critérios principais, pois a produção depende desses fatores. Assim a Farm Animal Welfare Council's (FAWC, 2009) propôs as chamadas 5 liberdades, sendo usadas de acordo com os sistemas de produção para prover a liberdade ao animal contra fome e sede, livre de desconforto, liberdade contra dor, ferimentos ou doenças, liberdade para expressar seus comportamentos normais e liberdade contra o medo e a angústia.

$\mathrm{Na}$ literatura, encontram-se duas abordagens principais ao estudo do comportamento animal e que são consideradas essenciais: a biológica e a psicológica. Neste trabalho é avaliado o comportamento psicológico, que se resume em estudar o comportamento e os fatores do ambiente, considerando o conceito de bemestar, que possam influenciar no desenvolvimento e no desempenho do comportamento das aves (pintainhos). 0 intuito dessa avaliação é analisar e qualificar se as aves estão em harmonia com o ambiente que as rodeia. Esses fatores podem ser medidos de forma objetiva e constituem uma importante estrutura de avaliação.

As próximas seções deste trabalho estão organizadas da seguinte forma: na seção 2 são apresentados os trabalhos correlatos que serviram de base para a aquisição de conhecimentos; na seção 3 são descritos os materiais e os métodos utilizados, como e com que frequência foram feitas as filmagens, bem como os processamentos de imagens realizados em cada frame para localização dos animais, os experimentos e estudos realizados para analisar os resultados obtidos; na seção 4 são apresentado os resultados e os problemas encontrados com a variação da iluminação não controlada; e, por fim, na seção 5 são apresentadas as conclusões e considerações finais do trabalho.

\section{TRABALHOS CORRELATOS}

Existem trabalhos desenvolvidos em todo o mundo sobre o comportamento de animais, alguns deles utilizam da tecnologia para auxiliar nas respostas. A pesquisa de Pereira (2005) utiliza monitoramento digital e construção de modelos de simulação a partir de imagens capturadas por câmeras de vídeo, instaladas no teto de um aviário. Com os vídeos foram observados os efeitos do ambiente (iluminação adequada para uma melhor produção), idade (adequada para procriação) e linhagem (resultados da seleção genética), nos comportamentos expressos pelas matrizes. A Figura 1 mostra o aviário usado pelo autor no experimento visto de cima. 


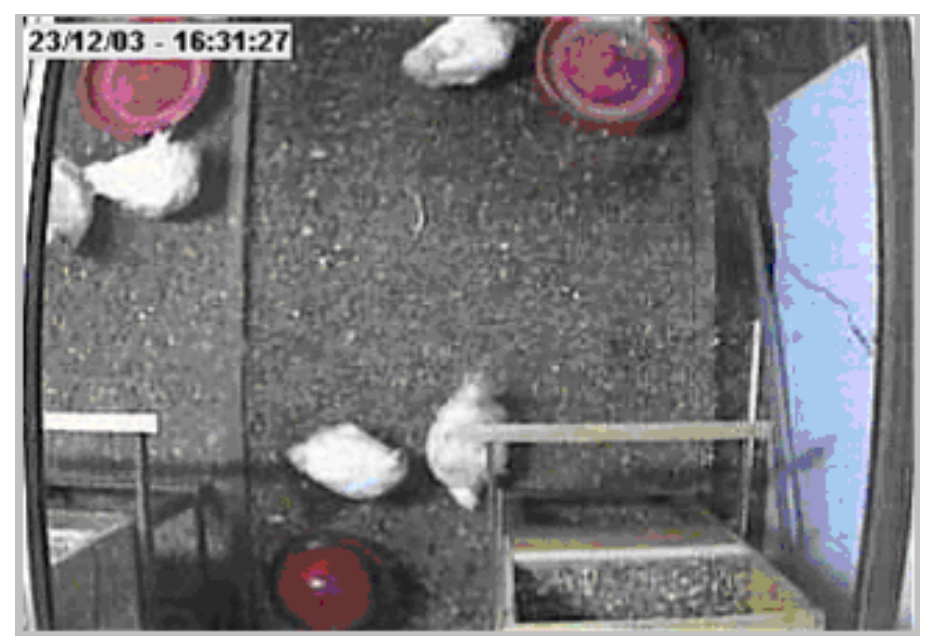

Figura 1. Imagem do aviário visto do teto.

Fonte: (PEREIRA, 2005).

A Figura 2 ilustra uma das telas do software usado na pesquisa de Pereira. O autor cria estimativas de bem estar em matrizes de frango de corte com o auxílio de um software desenvolvido em seu trabalho, sendo o mesmo alimentado manualmente com informações obtidas após uma análise visual dos vídeos coletados, permitindo o estudo da influência do ambiente no comportamento das matrizes.

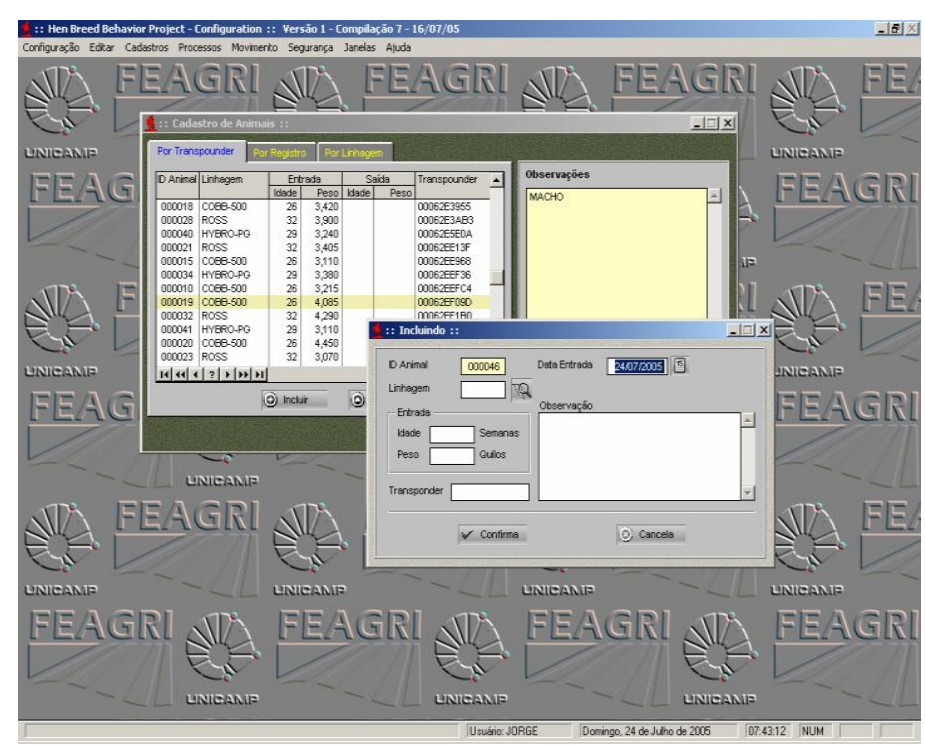

Figura 2. Imagem do software usado para gerar estimativas de bem-estar das matrizes. Fonte: (PEREIRA, 2005). 
Por outro lado, ainda existem trabalhos que registram o ambiente das aves (pintainhos) com o uso de câmeras de vídeo, como o trabalho de Falco (2010), mas as avaliações são realizadas posteriormente por uma análise visual a partir dos vídeos gravados. Os vídeos foram gravados num período de 22 horas seguidas, sendo analisadas em intervalos de 15 minutos. Os animais foram mantidos em dois regimes de criação, um com alta densidade (grande quantidade de aves) e desafio higiênico (o bebedouro e a cama não eram limpos diariamente), e outro com baixa densidade (baixa quantidade de aves) e sem desafio higiênico (o bebedouro e a cama eram limpos diariamente). Os vídeos desses dois regimes de criação foram analisados visualmente para se fazer uma avaliação das condições de níveis de bem-estar. A Figura 3 ilustra uma imagem de um frame de um dos vídeos analisados.

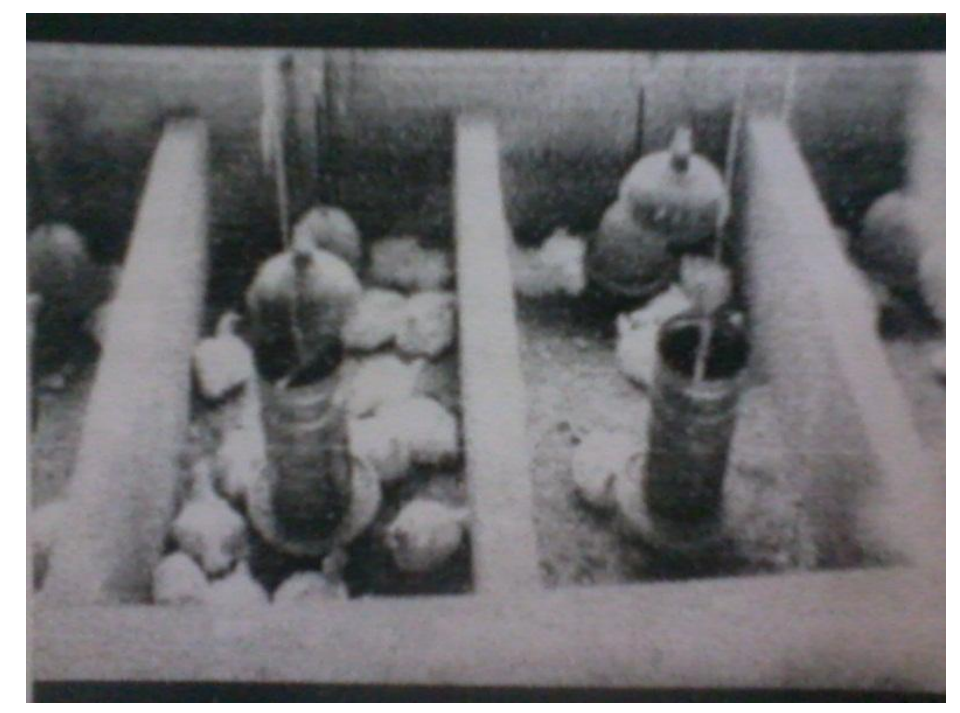

Figura 3. Imagem de um frame de vídeo analisada por Falco.

Fonte: (FALCO, 2010).

No trabalho, o autor analisa o comportamento das aves para ambos os tratamentos, com e sem desafio: se está sentada, ciscando, parada, explorando as penas e movimento de desconforto. $\mathrm{O}$ autor concluiu que sem desafio higiênico e sem a densidade alta influenciou $o$ padrão comportamental dos frangos de corte para uma melhor produção.

\section{MATERIAIS E MÉTODOS}

Os algoritmos e técnicas de Visão Computacional usados e implementados neste trabalho, aplicados nos frames dos vídeos, foram escritos na linguagem de 
programação Visual $\mathrm{C}++$, com o auxílio da biblioteca de Visão Computacional OpenCV (BRADSKI; KAEBLER, 2008).

\subsection{Aquisição de Imagem}

Para a aquisição das imagens foi usada uma câmera Microsoft LifeCam HD 500, instalada no teto do Aviário Experimental da Unoeste como mostrado na
Figura 4. A câmera foi disposta dessa forma para se ter uma visão ampla da baia de criação. Foram feitas filmagens para capturar os frames (quadros de imagens) durante as fases de criação das aves (pintainhos). Segundo Prado e Borges-Neto (2012) as fases ideais que devem ser acompanhadas são: Fase Inicial (1 a 21 dias), e Fase de Crescimento (22 até 42 dias).

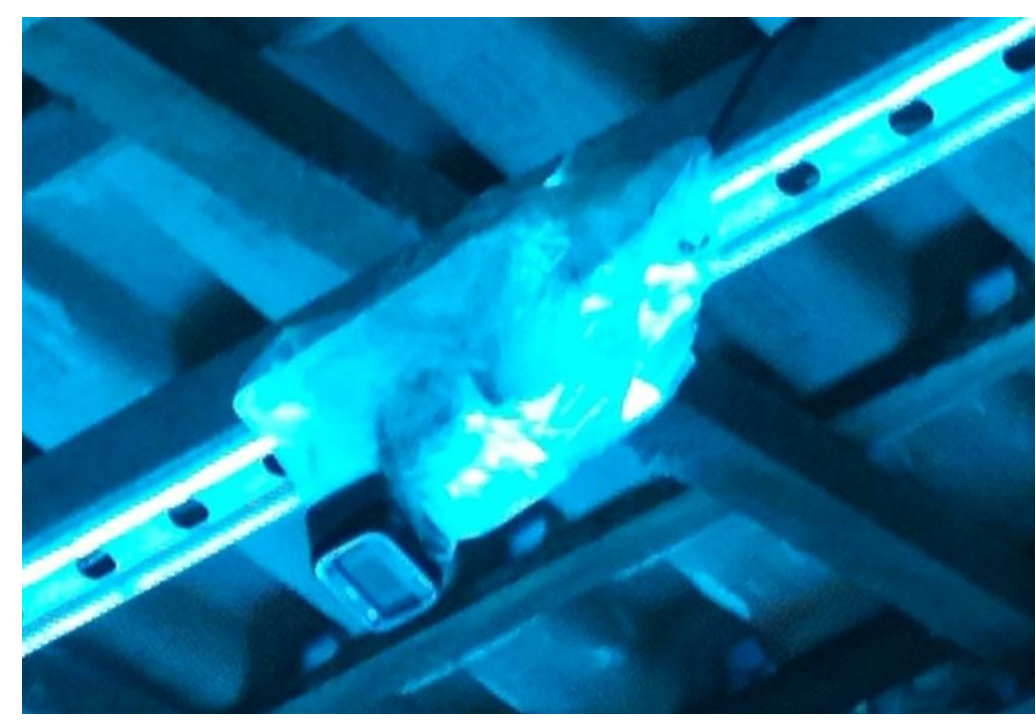

Figura 4. Câmera instalada no Teto do Aviário Experimental da Unoeste.

Foi usado um computador para criação, um a cada 3 segundos durante 20 armazenar os vídeos capturados como minutos, uma vez por semana durante 42 mostra a Figura 5, sendo estes adquiridos em dias.

determinados momentos durante as fases de 


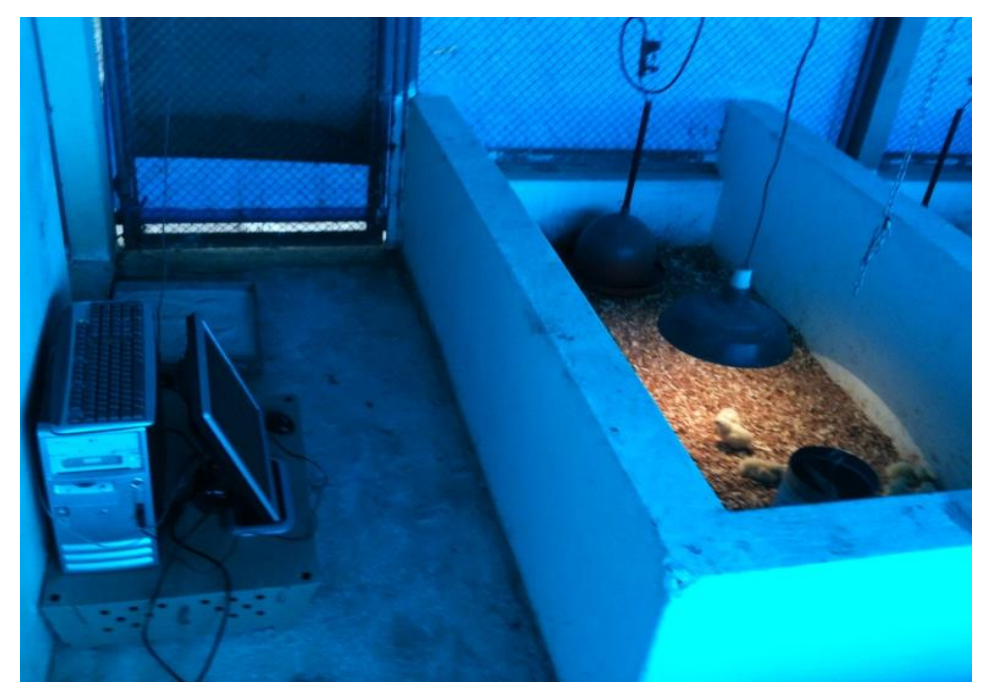

Figura 5. Baia de criação dos pintainhos, com a imagem do computador utilizado para armazenar os vídeos, capturados durante as fazes de criação.

A partir dos vídeos, foram feitas análises em cada frame na busca do comportamento das aves, para se ter informações das condições da ambiência em que as aves se encontram, e com isso verificar se está adequada ou não para uma boa criação das aves. A Figura 6 ilustra a baia de criação utilizada para capturar os vídeos durante as fases de criação.

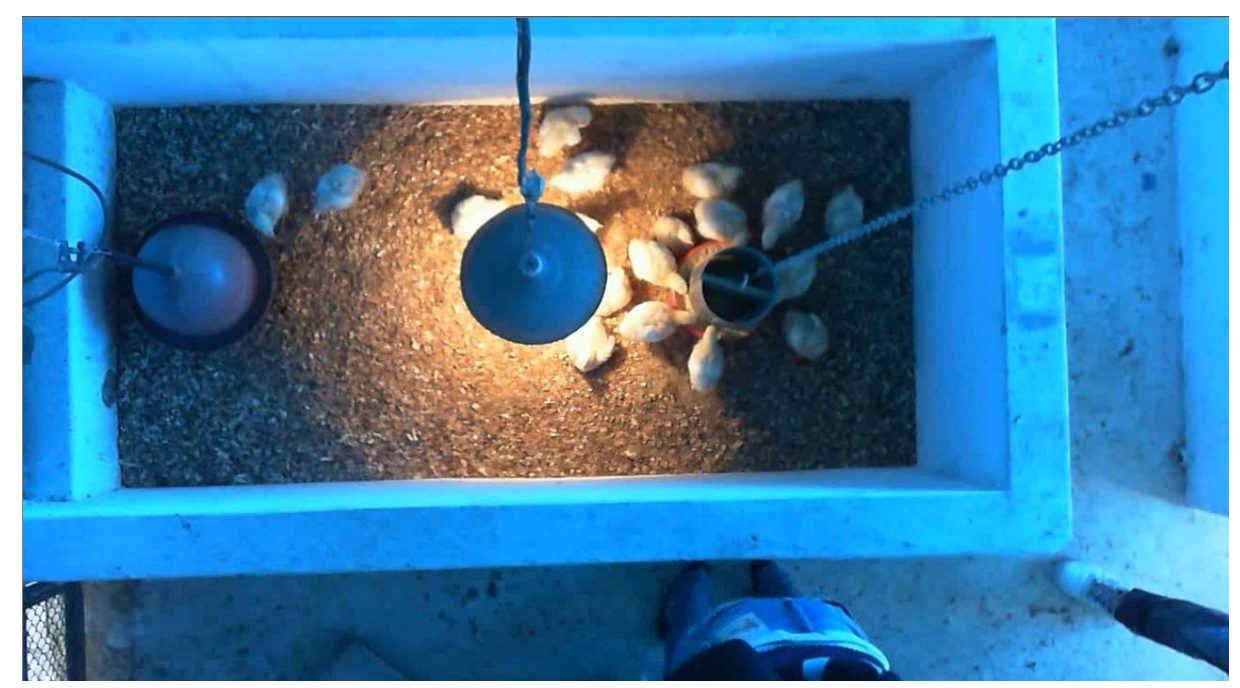

Figura 6. Baia de criação usada para capturar os vídeos durante as fases de criação.

Em cada frame de vídeo, inicialmente, foi recortada (segmentada) a área de interesse, que corresponde à baia de criação.
Com a imagem recortada (Figura 7), são realizados os seguintes procedimentos para realizar a localização das aves: conversão do 
espaço de cores de RGB para HSI, diminuição da iluminação no centro da imagem onde está localizada a luz de aquecimento da baia, transformação da imagem para negativo.

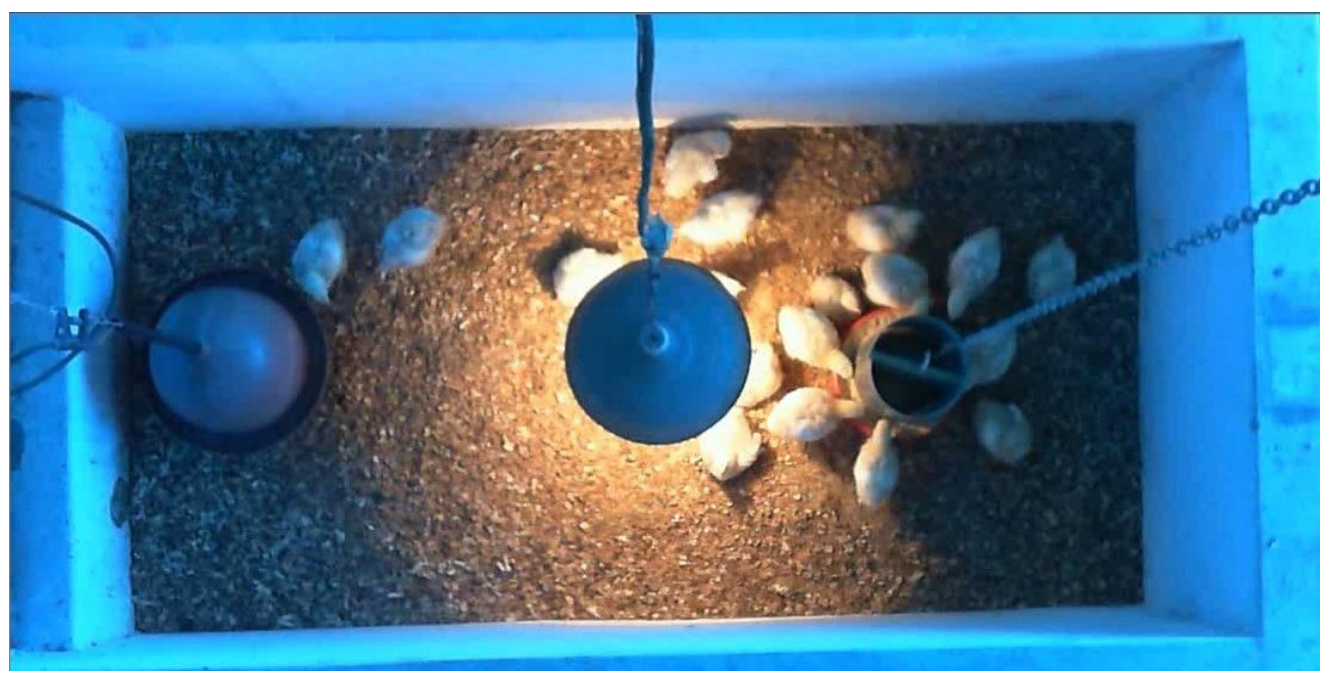

Figura 7. Imagem de um frame recortado com a região de interesse.

No Aviário Experimental da Unoeste são utilizadas cortinas azuis, assim a iluminância tende a ficar mais baixa, se comparada com uma cortina amarela (que também pode ser usada), ou mesmo sem a utilização de cortina. Segundo Vercelino (2012), o comportamento das aves tende a ser mais calmo quando são utilizadas as cortinas azuis, o que diminui as atividades dos animais, melhora a conversão alimentar ${ }^{2}$ e consequentemente a produtividade.

A concentração de luz no centro da baia (Figura 7), necessária para 0 aquecimento das aves, foi um dos grandes desafios encontrados. Essa concentração de luz causou dificuldades nas etapas de processamento das imagens dos frames. Para

\footnotetext{
${ }^{2}$ Conversão Alimentar: Quantidade de ração utilizada em um período de tempo (CANEIRO, 2004).
}

amenizar o problema, foi feita uma correção de iluminação, no caso um escurecimento nessa região, primeiramente, com a transformação do espaço de cores de RGB (Red, Green, Blue) para HSI (Matiz (Hue), Saturaçao (Saturation), Intensidade (Intensity)). As Equações (1), (2) e (3) demonstram essa transformação (GONZALEZ; WOODS, 2000). 


$$
\begin{aligned}
& H=\left\{\begin{array}{cc}
\theta & \text { se } B \leq G \\
360-\theta & \text { seB }>G
\end{array}\right\} \\
& \theta=\cos ^{-1}\left\{\frac{\frac{1}{2}[(R-G)+(R-B)]}{\left[(R-G)^{2}+(R-B)(G-B)\right]^{\frac{1}{2}}}\right\} \\
& S=1-\frac{3}{(R+B+G)}[\min (R, G, B)] \\
& I=1 / 3(R+G+B)
\end{aligned}
$$

O espaço de cores $\mathrm{HSI}$, se relaciona com a forma com que os humanos descrevem e interpretam as cores. Sendo:

- H (Matiz): é a cor pura e é expressa em graus de ângulo, onde 0 é a cor vermelha;
- S (Saturação) é a diluição da cor pura em branco;

- I (Intensidade ou Brilho) nível de cinza.

A Figura 8 ilustra o modelo $\mathrm{HSI}$ baseado em plano de cores circular.

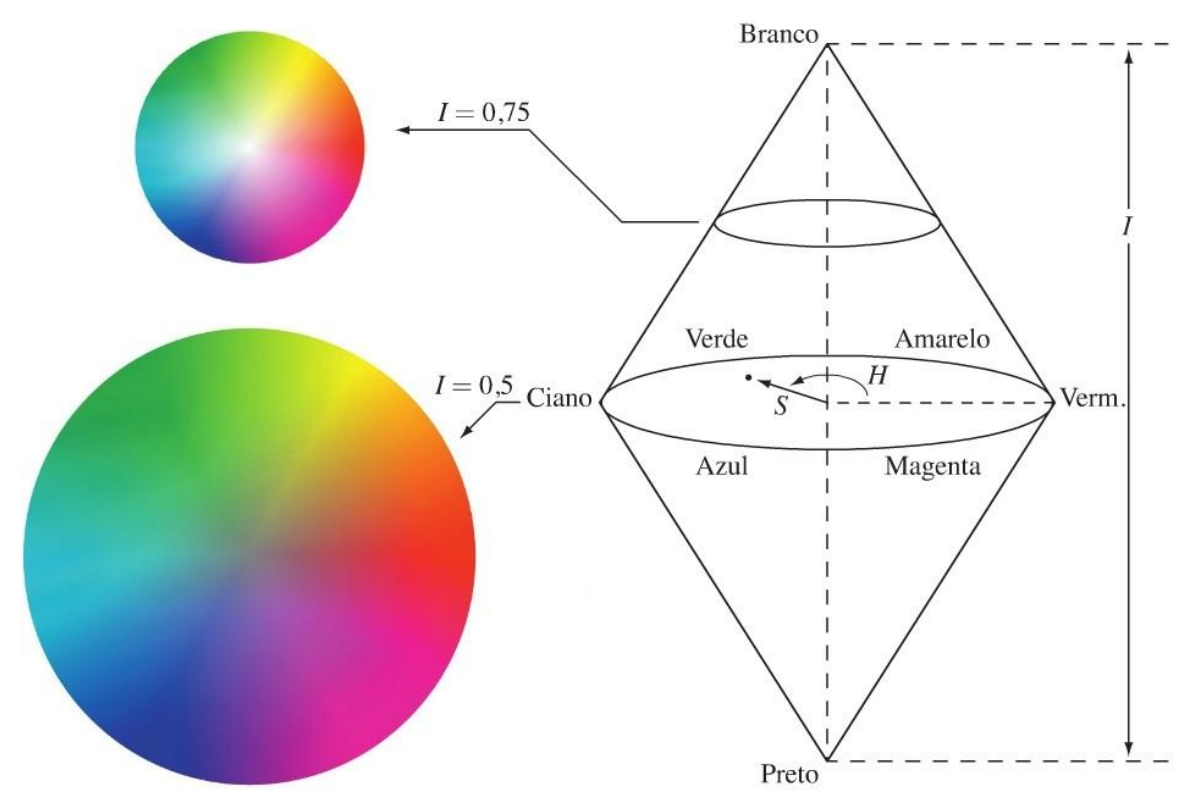

Figura 8. O modelo de cores HSI baseado em planos de cores.

Fonte: (GONZALEZ; WOODS, 2000). 
Como a iluminação é mais intensa nas proximidades no ponto de luz de aquecimento da baia de criação (localizada na região central da baia) e vai diminuindo essa intensidade ao se afastar deste ponto, houve a necessidade de corrigir essa iluminação de uma forma circular e gradual. Para isso, foi utilizada a equação da circunferência com centro na origem e raio $R$, que em coordenadas cartesianas, é dada por:

$$
x^{2}+y^{2}=R^{2}
$$

A Figura 9 representa a técnica utilizada para redução da iluminação no centro da imagem, sendo o raio $R$ iniciando do valor 70 e indo até 275. A intensidade é diminuída em $40 \%$ no centro da imagem (começando a partir do ponto de luz) e a cada iteração, a porcentagem da intensidade vai diminuindo em um fator de 0.4/205 até chegar em $0 \%$, em que o raio chegará a ter o valor 275 .

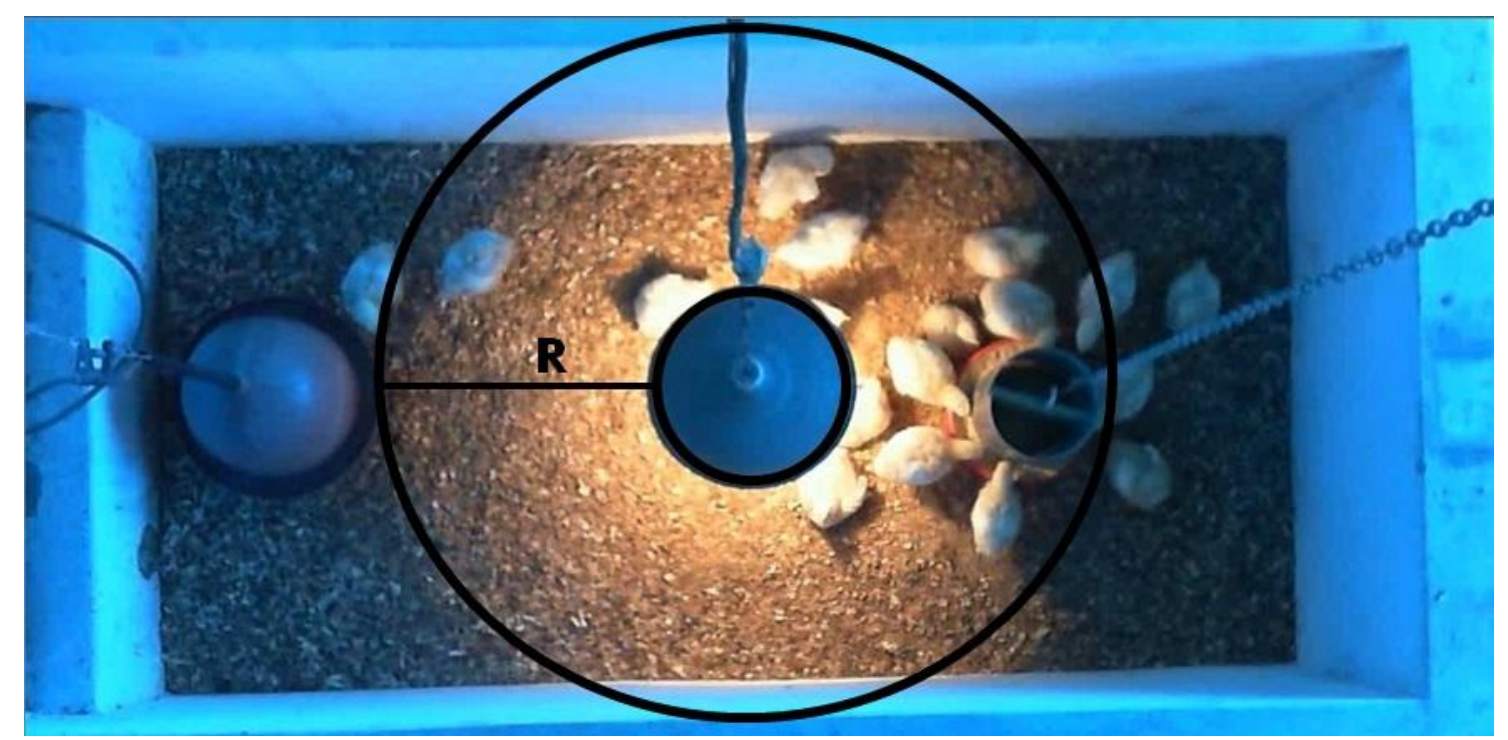

Figura 9. Representação da região circular a ser corrigida a iluminação, sendo $R$ o raio dessa região.

A Figura 10 mostra o resultado da aplicação do processo de correção da iluminação da imagem da baia de criação.
Procedimento esse estritamente necessário para os outros procedimentos seguintes. 


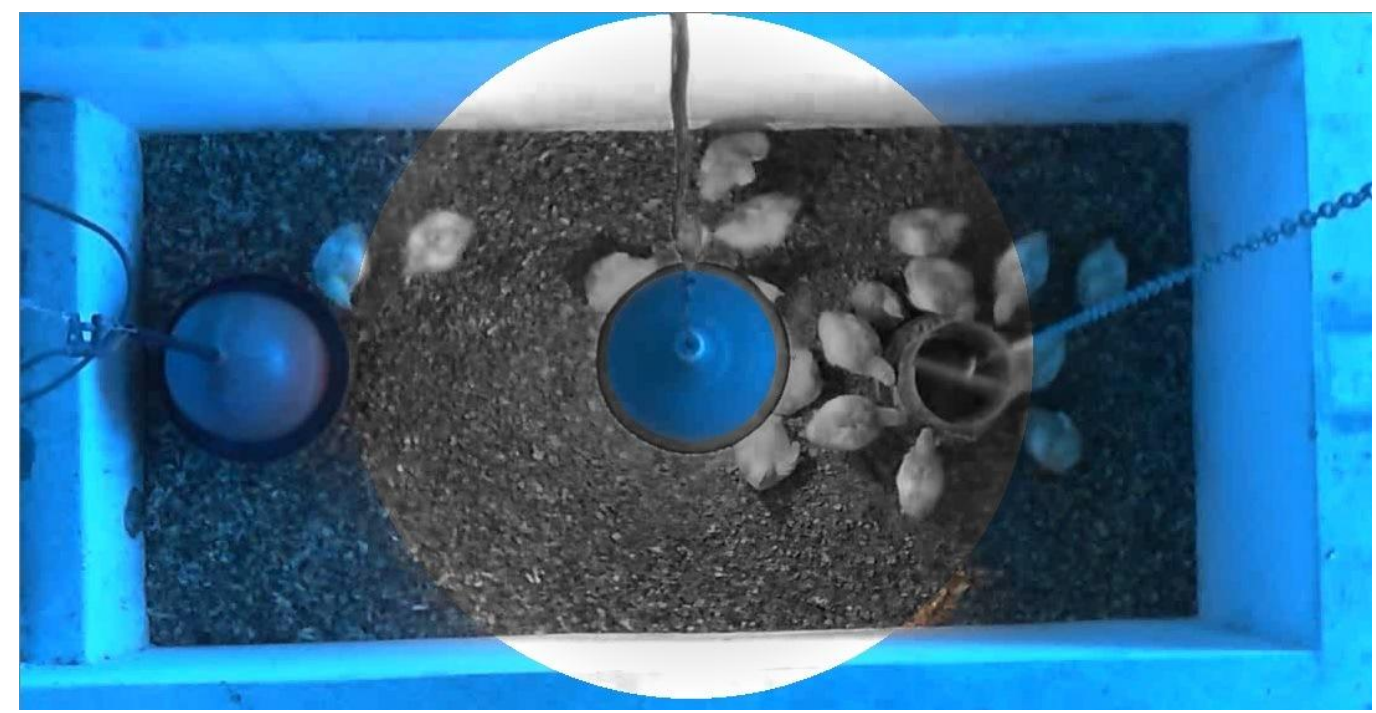

Figura 10. Resultado da aplicação da correção da intensidade.

Em seguida foi realizada a aplicação do negativo na imagem (Equação (5)), isso ocorre com imagens em níveis de cinza, com o objetivo de realçar detalhes brancos ou cinzas incorporados como mostrado na Figura 11.

$$
g(x, y)=W-f(x, y)
$$

onde $f(x, y)$ representa a imagem original, $g(x, y)$ representa a imagem transformada, e $W$ equivale ao valor máximo de intensidade dos pixels.

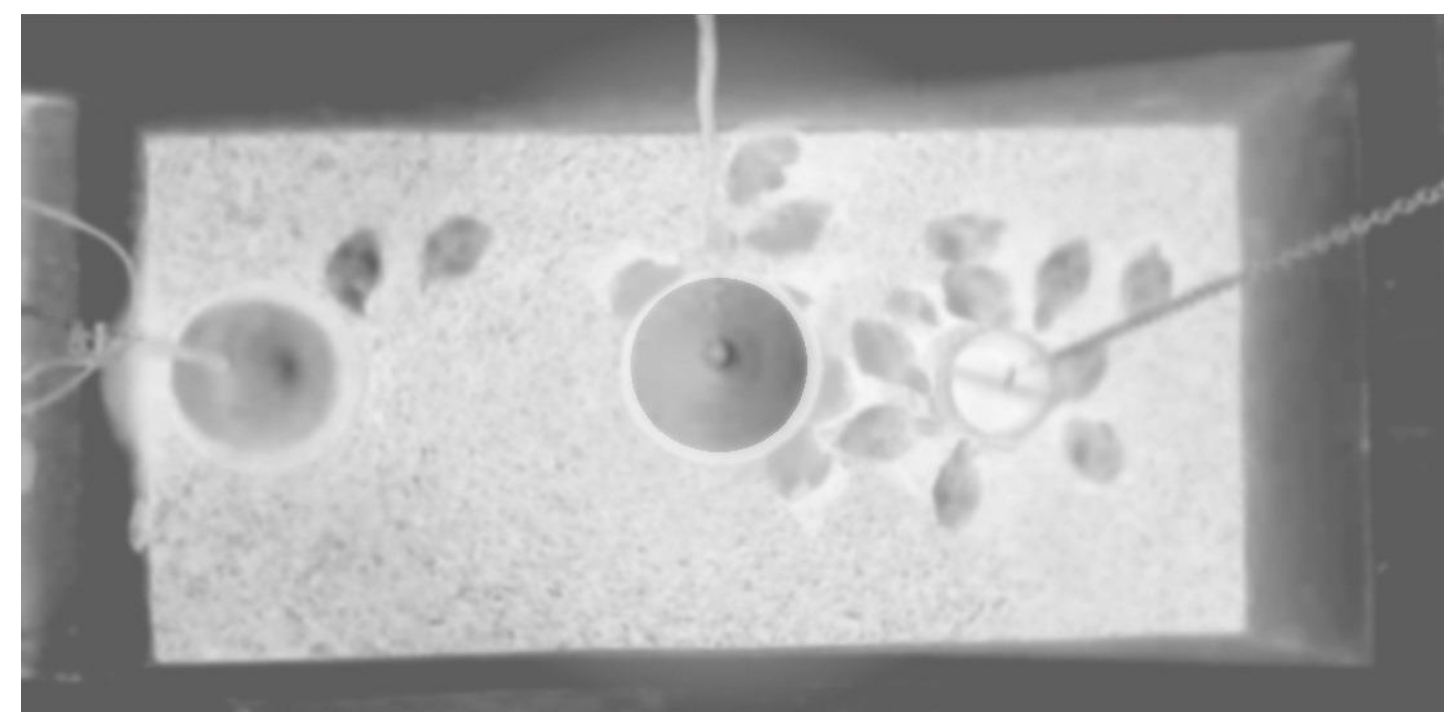

Figura 11. Imagem resultante após a aplicação do negativo.

Para a localização dos animais, foi realizada a subtração da imagem de cada frame com a imagem do fundo (baia de criação sem a presença das aves). Os mesmos procedimentos aplicados às imagens dos frames de vídeo para corrigir a iluminação da 
região central e torná-las imagens negativas, foram aplicados à imagem do fundo da baia de criação. A Figura 12 ilustra a imagem original do fundo da baia de criação sem a presença das aves.

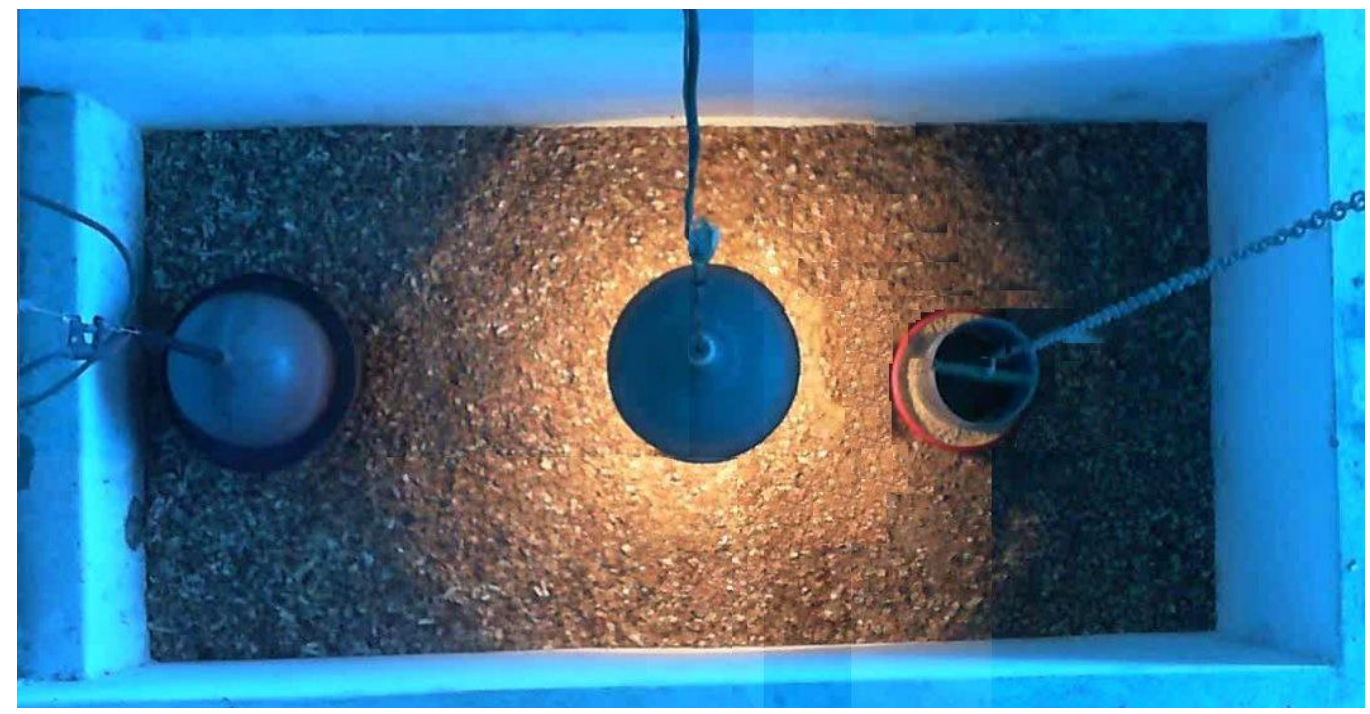

Figura 12. Imagem original do fundo da baia de criação sem as aves.

A Figura 13 ilustra a imagem do fundo da baia de criação após a correção de iluminação do centro, onde se localiza a luz destinada ao aquecimento das aves.

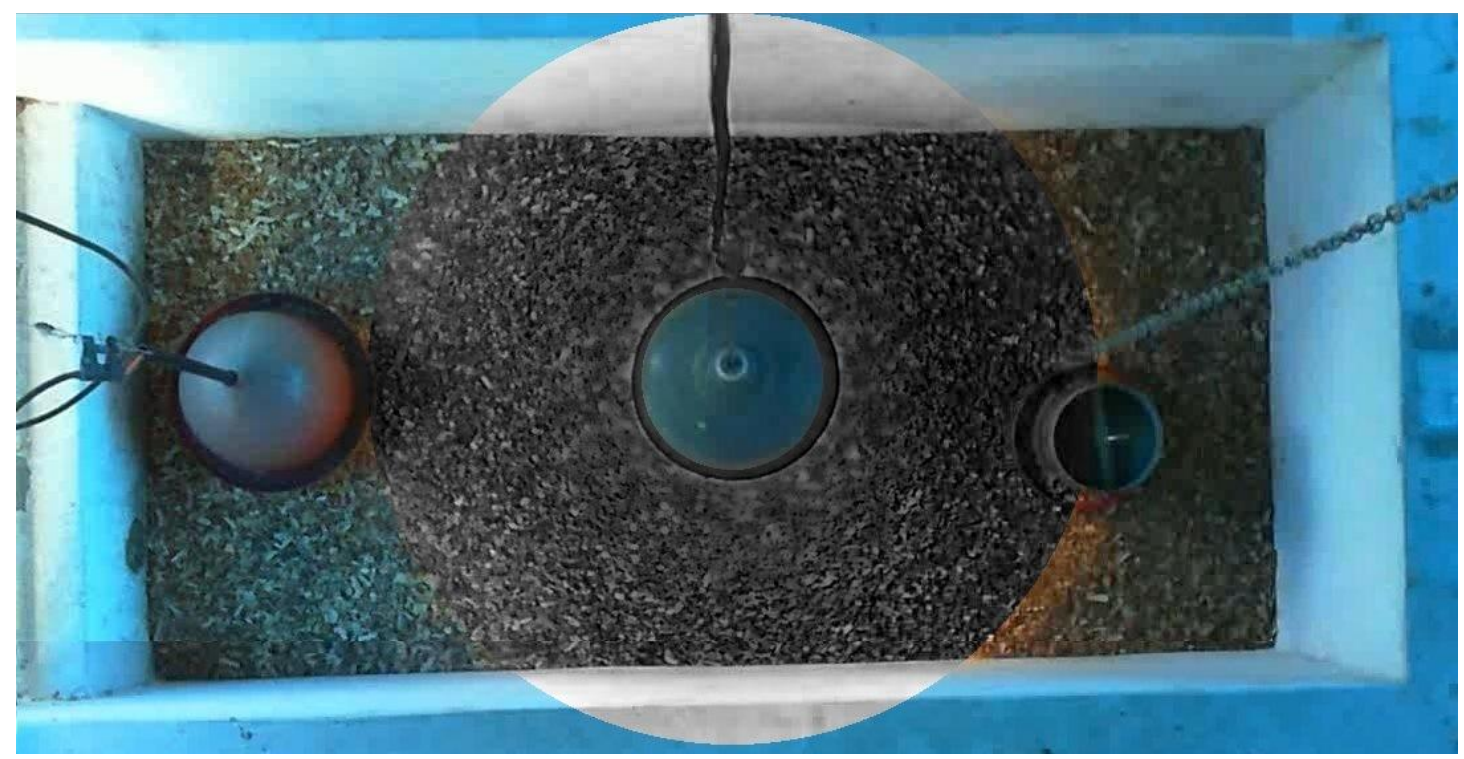

Figura 13. Fundo da imagem após o escurecimento do centro da baia para correção da iluminação.

Na Figura 14, está representada a imagem do fundo da baia após todos os procedimentos de correção de iluminação e aplicação do negativo. 


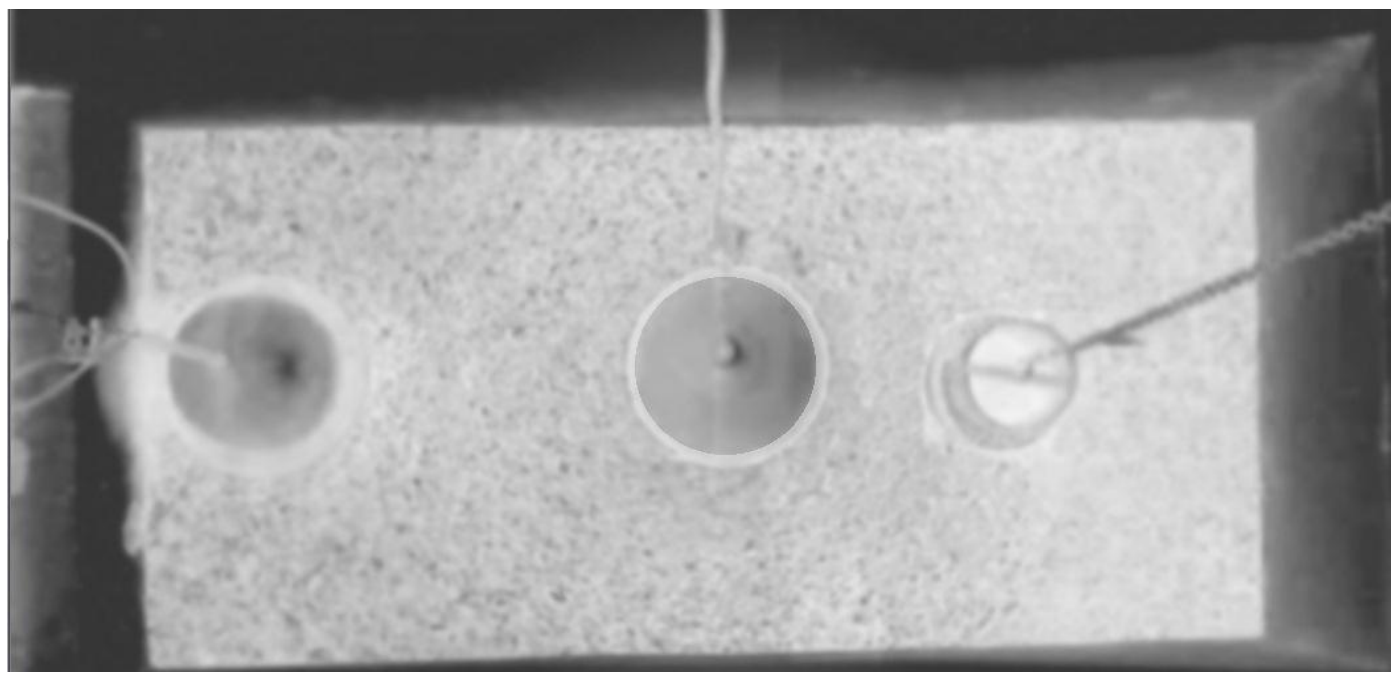

Figura 14. Fundo da imagem após a aplicação do negativo.

Foi realizada a subtração do negativo da imagem processada (Figura 11), após todos os procedimentos, com o negativo do fundo (Figura 14), usando para isso a Equação (6).

$$
f(x, y)=g(x, y)-h(x, y)
$$

onde $f(x, y)$ é a imagem resultado da subtração, $g(x, y)$ é a imagem atual e $h(x, y)$ é o fundo da imagem.

A Figura 15 mostra o resultado da subtração da imagem em negativo de um frame com a imagem em negativo do fundo da baia.

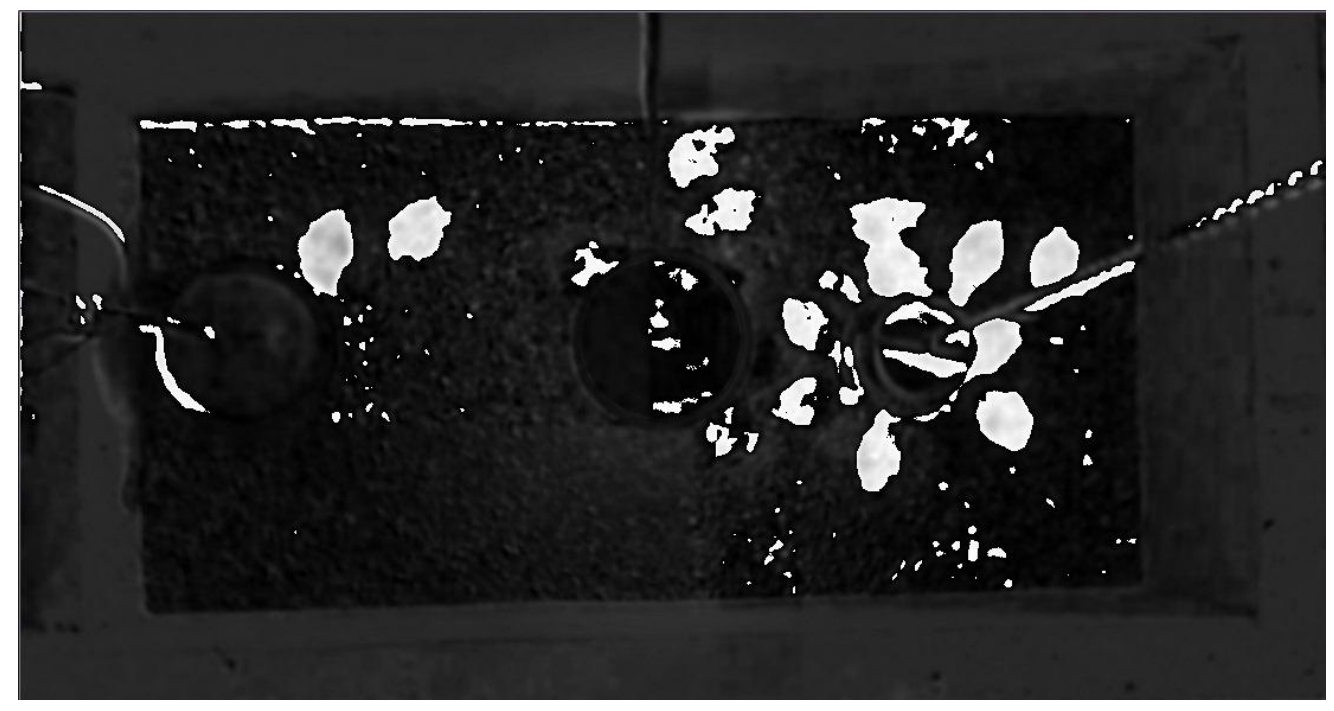

Figura 15. Resultado da subtração entre a imagem de um frame com a imagem do fundo da baia de criação, ambos em negativo. 
Após a subtração, foi realizado o processamento morfológico ${ }^{3}$ para eliminar os elementos de tamanhos pequenos que não representam as aves buscadas na imagem. Neste trabalho foi utilizada a operação denominada Fecho, que é a combinação de duas operações morfológicas, a dilatação e a erosão.

A dilatação (Equação (7)) e a erosão (Equação (8)) são operações morfológicas primitivas, obtidas por varrimento da imagem com uma máscara ou com elemento estruturante.

A dilatação (Equação (7)) tende a fechar os buracos na imagem original, expandindo as regiões dos pixels, criando objetos maiores.

$$
A \oplus B=\left\{z \mid(B)_{x} \cap A \neq \varnothing\right\}
$$

onde $A$ e $B$ são conjuntos de $Z^{2}$ e $\varnothing$ é o conjunto vazio. O conjunto $B$ normalmente é o elemento estruturante.

A erosão (Equação (8)) tende a remover objetos pequenos (irrelevantes) por remoção de pixels.

$$
A \Theta B\left\{x \mid(B)_{x} \subseteq A\right\}
$$

onde $A$ e $B$ como conjuntos de $Z^{2}$, a erosão de $A$ por $B$, denotada por $A \Theta B$, é o conjunto de todos os pontos $z$ de forma que $B$ quando transladado por $z$ fique contindo em $A$.

$$
\text { O Fecho (Equação (9)) é a operação }
$$
de dilatação seguida da operação de erosão, em que tende a suavizar os contornos, eliminando pequenos buracos irrelevantes e preenchendo lacunas em um contorno (GONZALEZ; WOODS, 2000).

$$
A \bullet B=(A \oplus B) \Theta B
$$

onde $A$ é um subconjunto (sub-imagem) de $A$ - B. A Figura 16 ilustra o resultado da operação morfológica Fecho aplicado na imagem.

\footnotetext{
${ }^{3}$ Processamento morfológico: define um conjunto de operações de imagem, que modificam a estrutura espacial (forma) dos objetos dentro de uma imagem, preservando as características da forma de um objeto, eliminando os detalhes irrelevantes, como tal oferece uma abordagem unificada e poderosa para vários problemas de processamento de imagem (GONZALEZ; WOODS, 2000).
} 


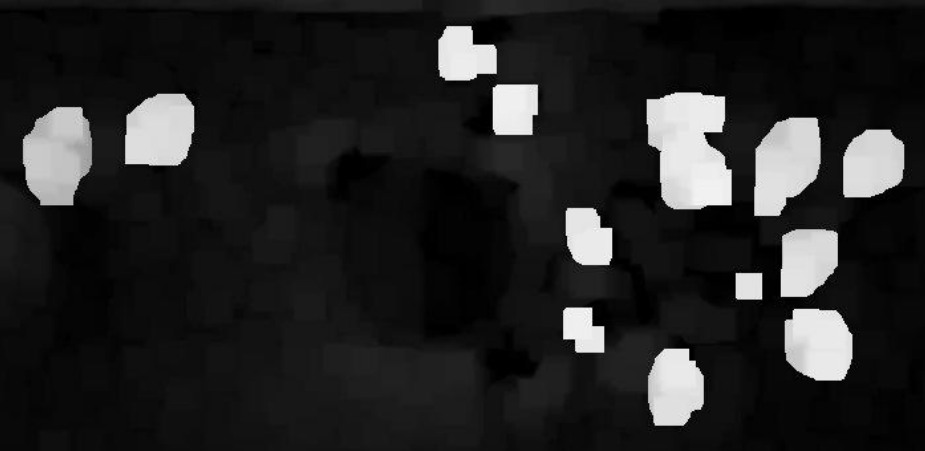

Figura 16. Resultado da operação Fecho aplicado na imagem.

Em seguida foi realizada a Após a aplicação da limiarização, os pixels limiarização, com um valor de limiar igual a que representam as aves ficaram todos 150 definido empiricamente para obter brancos, como mostra na Figura 17. apenas os grupos de pixels acima desse valor.

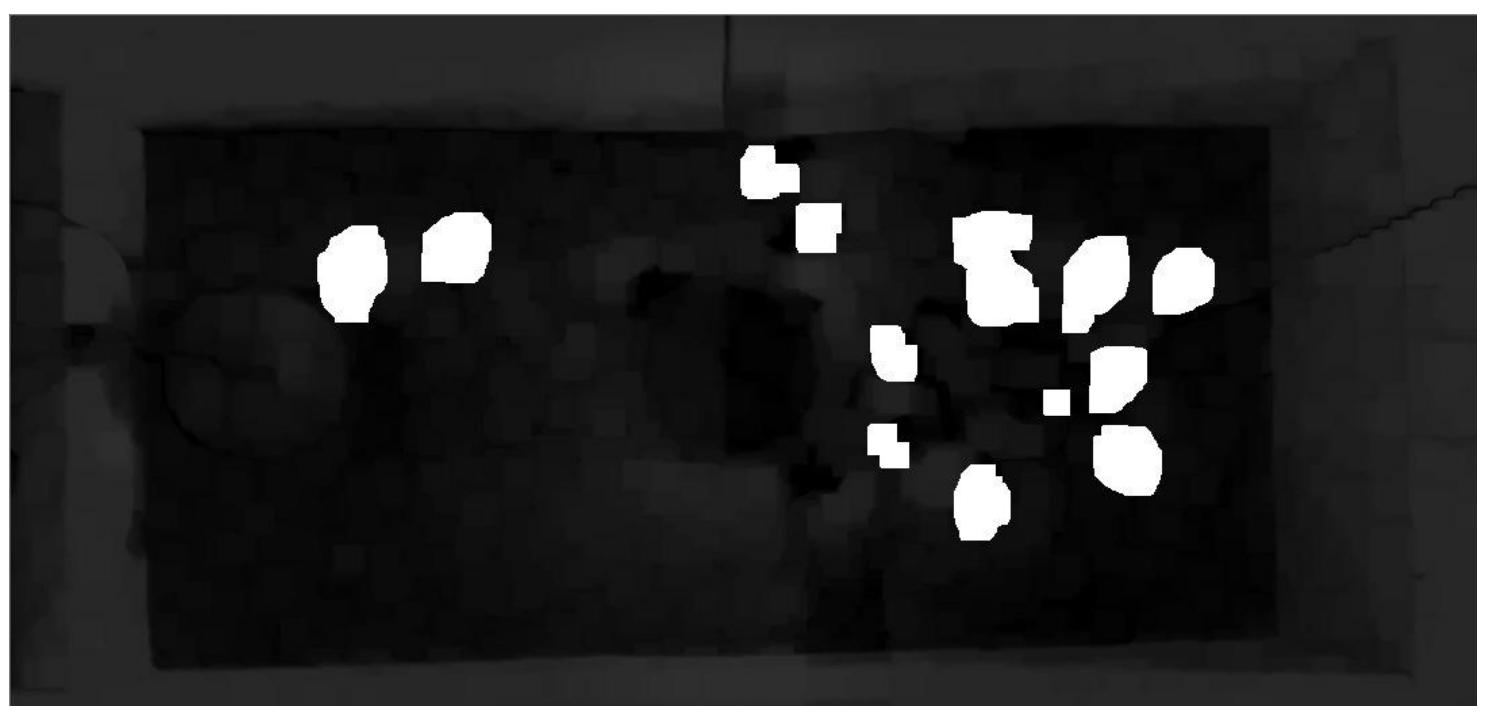

Figura 17. Resultado da limiarização.

Na Figura 18 encontram-se ilustradas as divisões da baia em três partes, sendo elas: bebedouro, luz de aquecimento e comedouro. Essas divisões na imagem foram feitas para se determinar as regiões de interesse da baia de criação, e com isso quantificar a frequência com que os pintainhos permanecem em cada parte da 
baia. Essas quantidades são usadas para se determinar a presença das aves em cada uma dessas regiões a cada momento, para que esses dados sejam usados posteriormente para análises. (a)

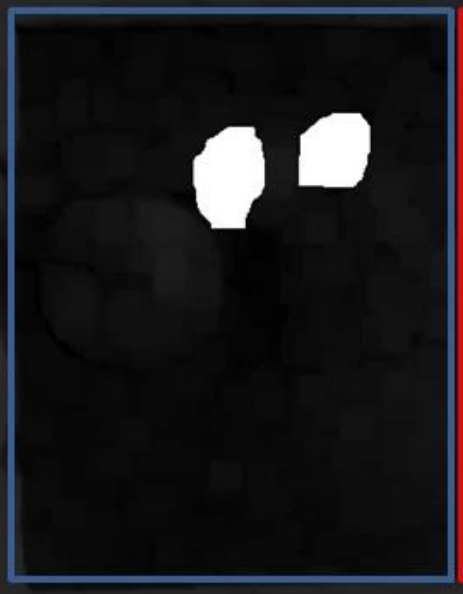

(b)

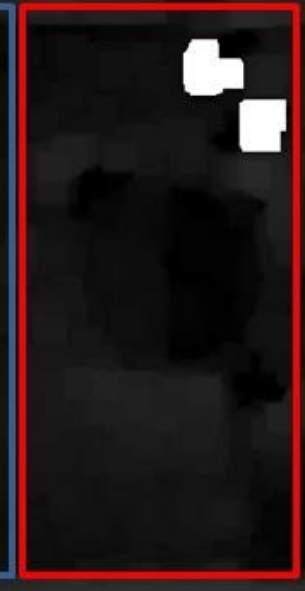

(c)

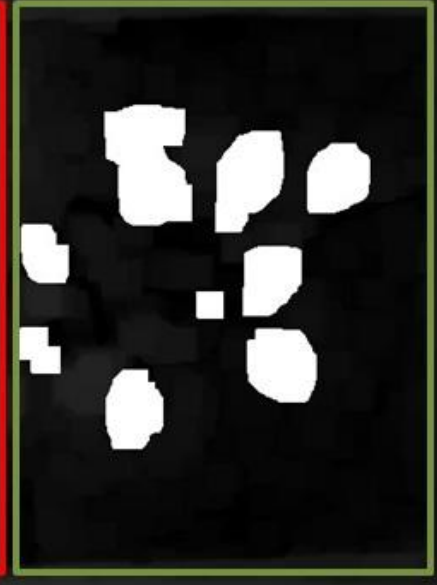

Figura 18. Divisão da baia de criação das aves. (a) bebedouro, (b) luz de aquecimento, e (c) comedouro.

Depois de realizada a divisão da baia, a imagem é mapeada, usando um algoritmo de inundação (GONZALEZ; WOODS, 2000), que a partir de um de um início (um ponto dentro da região a ser inundada) de uma cor alvo (branco) e de uma cor para substituição (azul se a ave estiver no bebedouro, vermelho se a ave estiver na luz de aquecimento e verde se a ave estiver no comedouro), é realizado o preenchimento dos pixels. Com a região de cada ave mapeada, é calculada a massa de cada ave, assim quantificando as aves em cada parte. Deduz-se que as aves que não foram mapeadas, estariam em baixo da luz de aquecimento.

A Figura 19 ilustra o resultado do algoritmo de inundação após o mapeamento da imagem e determinação da cor de substituição em cada parte da baia, destacando assim as aves. 


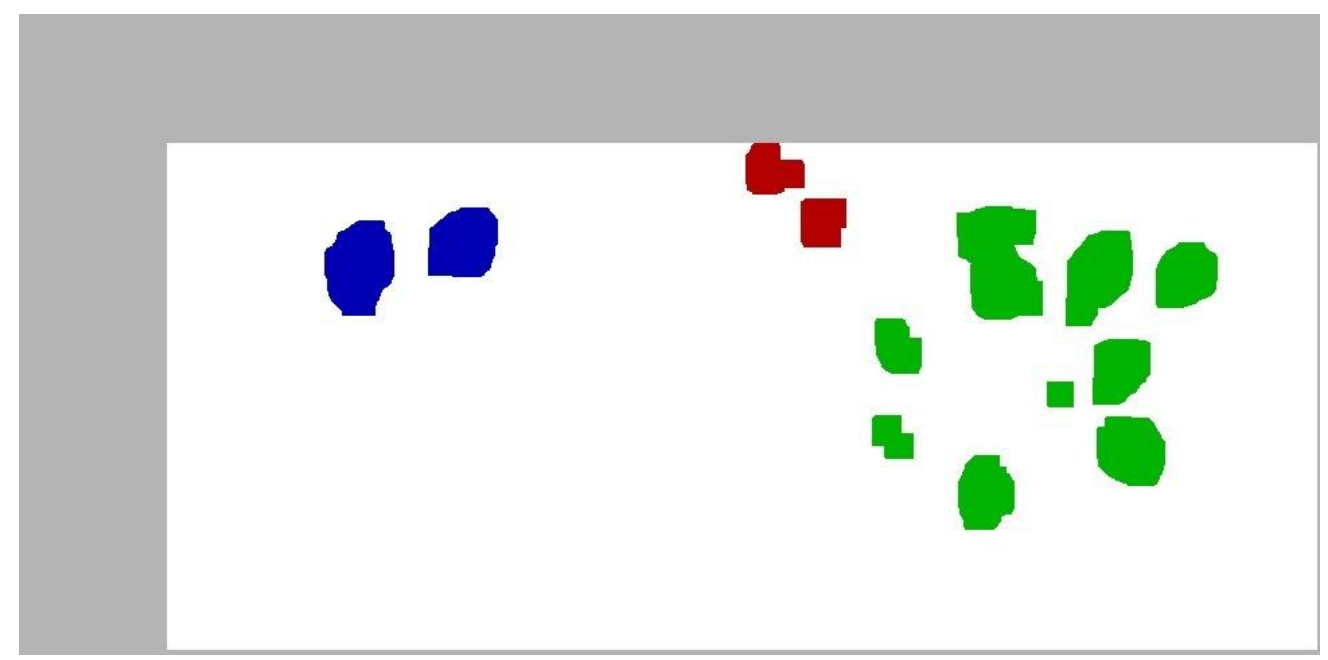

Figura 19. Resultado do algoritmo de inundação após o mapeamento da imagem.

A partir do conhecimento calculado das posições das aves na baia de criação, foram gerados as seguintes informações: tempo do vídeo, números de aves no bebedouro, na luz de aquecimento e no comedouro (Figura 20).

$$
\begin{aligned}
& 1,9,9,2 \\
& 4,9,10,1 \\
& 7,10,10,0 \\
& 10,9,11,0 \\
& 13,9,11,0 \\
& 16,9,11,0 \\
& 19,8,12,0 \\
& 22,7,13,0 \\
& 25,6,14,0 \\
& 28,8,12,0 \\
& 31,10,10,0 \\
& 34,10,10,0 \\
& 37,8,12,0 \\
& 40,7,13,0 \\
& 43,8,11,1 \\
& 46,8,11,1 \\
& 49,10,9,1 \\
& 52,10,8,2 \\
& 55,10,8,2 \\
& 58,9,9,2 \\
& 61,10,7,3 \\
& 64,7,11,2 \\
& 67,8,11,1 \\
& 70,8,11,1 \\
& 73,8,11,1 \\
& 76,7,12,1 \\
& 79,8,10,2 \\
& 82,8,10,2 \\
& 85,8,10,2 \\
& 88,9,9,2 \\
& 91,11,7,2 \\
& 94,8,10,2 \\
& 97,12,6,2 \\
& 100,10,9,1 \\
& 103,11,8,1 \\
& 106,9,10,1
\end{aligned}
$$

Figura 20. Quantidade de pintainhos em cada parte da baia em determinado tempo. 
No experimento realizado, foi visualização da frequência em que os utilizado o vídeo da terceira semana de pintainhos permaneciam em determinado criação, pois o mesmo estava em melhor ambiente. A Figura 21 mostra o gráfico que condição em questão de iluminação. foi gerado.

Para a análise dos resultados, foi gerado um gráfico para se ter uma melhor

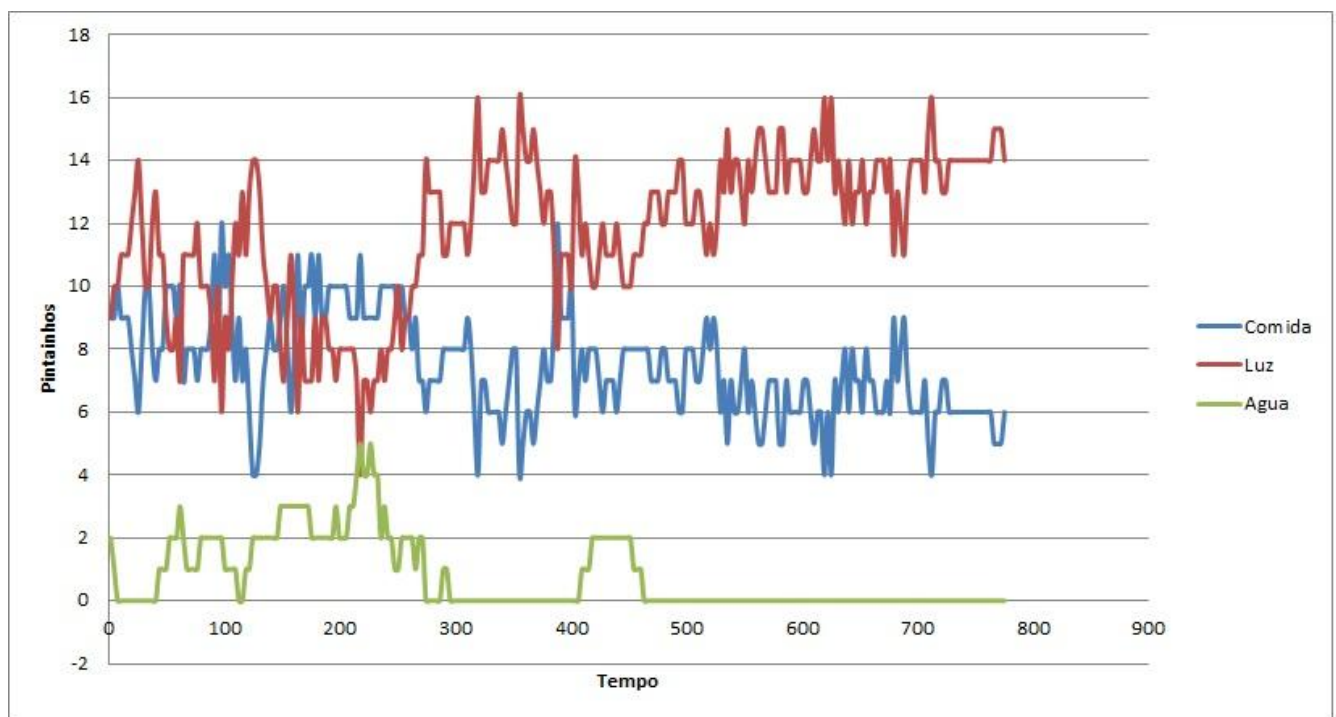

Figura 21. Gráfico em que as aves permanecem em determinado ambiente.

A Figura 22 apresenta um gráfico que demonstra o somatório das frequências em que as aves estiveram presentes em determinados locais na baia de criação ao longo do tempo. Esse somatório das frequências foi obtido a partir da análise em todos os frames do vídeo utilizado no experimento. 


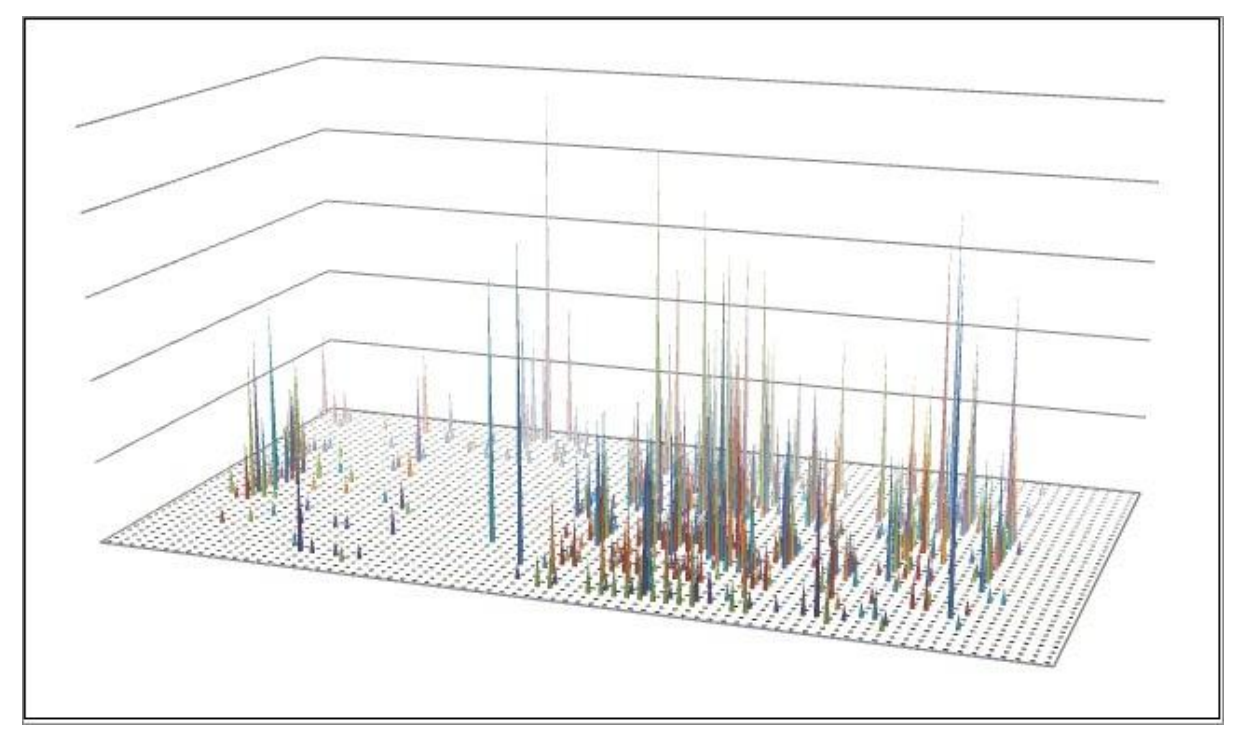

Figura 22. Gráfico do somatório das frequências das aves na baia de criação.

É importante ressaltar que este trabalho consiste em apenas monitorar, por meio de filmagens, alguns momentos da criação das aves para análise posterior, e não fazer experimentos com animais.

\section{RESULTADOS E DISCUSSÃO}

Os resultados foram analisados de acordo com os comportamentos coletados pelas imagens obtidas com os vídeos. Durante as análises dos quadros foram encontrados vários desafios, sendo eles a utilização de cortinas azuis nas baias de criação, que deixavam o ambiente com baixa iluminação, e no dia em que foram feitas as filmagens, o tempo estava fechado e com pouca iluminação. Outros fatores dificultosos foram a alta iluminação central causada pela lâmpada que aquece as aves, os objetos não serem fixos e o tipo de cama utilizada.

\section{CONCLUSÕES}

Este trabalho apresenta a frequência em que as aves permanecem em determinado local ao longo do tempo filmado, e que, com recursos computacionais é possível analisar e monitorar avicultura. Acredita-se que o uso da tecnologia pode poupar o trabalho humano não tendo a necessidade de uma pessoa ficar observando, e ter o mesmo resultado.

Através de experimento realizado pode-se concluir que por se tratar de um dia chuvoso e com temperaturas baixas, a aves procuravam aquecer-se na maior parte do tempo filmado. Isso explica a presença das aves a maior parte do tempo, como pode ser observado no gráfico da Figura 21.

Essa pesquisa abre portas para novas pesquisas, sendo possível analisar as aves em outras condições de ambiente e com outras estimativas. Além da frequência, como foi 
realizado neste trabalho, pode-se analisar as aves separadamente, atividade essa que pode ser auxiliada com a utilização de marcações individuais.

\section{REFERÊNCIAS}

BRADSKI, G.; KAEBLER A. Learning OpenCV: computer vision with the OpenCV Library. United States of America: O'Reilly, 2008.

CARNEIRO, S. L. et al. Frango de corte: integração produtor/ indústria. Paraná: [s.n], 2004.

FALCO, D. C. Estudo comportamental de frangos de corte criados sob diferentes condições de densidade e manejo higiênico. Presidente Prudente: Unoeste, 2010.

FARM ANIMAL WELFARE COUNCIL (FAWC). 2009. Disponível em: <http://www.fawc.org.uk/freedoms.htm>. Acesso em: 03 abr. 2012.

GONZALEZ, R. C.; WOODS, R. E. Processamento de imagens digitais. São Paulo: Blucher, 2000.

NÄÄS, I. A. et al. Ambiência aérea em alojamento de frangos de corte: poeira e gases. Engenharia Agrícola, Jaboticabal, v.27, n. 2, p.326-335, 2007.

NÄÄS, I. A. Avanços de bem-estar na produção de frangos de corte. In: 60 Encontro Mercolab de Avicultura 6. Anais... Cascavel, Paraná, 2008.

PEREIRA, D. F. Metodologia para estimativa de bem-estar de matrizes de frango de corte utilizando monitoramento digital e construção de modelos de simulação. 2005. Tese (Doutorado em Engenharia Agrícola) Universidade Estadual de Campinas, SP.
PEREIRA, D. F. Ambiência em frango de corte. Tupã: Campus Experimental de Tupã UNESP, 2011.

PRADO G. F; BORGES-NETO J. P. Cartilha do produtor. BIGSAL - Nutrição Animal. Disponível em: http://www.bigsal.com.br/manejo-alimentarde-frangos-de-corte.php. Acessado em: 27 mar. 2012.

SOUTO, A. Etologia: princípios e reflexões. Recife: Editora Universitária da UFPE, 2005.

VERCELINO, R. A. Efeito de diferentes sistemas de vedação de aviários no comportamento e bem estar de frangos de corte. Campinas: Faculdade de Engenharia Agrícola - FEAGRI, 2012. 